\title{
Analysis of a Vertical Flat Heat Pipe Using Potassium Working Fluid and a Wick of Compressed Nickel Foam
}

\author{
Geir Hansen *, Erling Næss ${ }^{\dagger}$ and Kolbeinn Kristjansson ${ }^{\dagger}$ \\ Department of Energy and Process Engineering, Norwegian University of Science and Technology, \\ Kolbjørn Hejes vei 1a, Trondheim 7491, Norway; erling.nass@ntnu.no (E.N.);

Keywords: aluminum electrolysis cell; heat pipe; compressed nickel foam wick; potassium; hot spot analysis

\section{Introduction}

The current study originated from an industrial demand for heat recovery from electrolysis cell side-linings at temperatures in the range $400-650{ }^{\circ} \mathrm{C}$. In aluminum electrolysis, about $50 \%$ of the total supplied energy is currently lost as heat to the surroundings. About $35 \%$ of the total heat loss is through the walls of the electrolysis cells [1], which corresponds to $c a .2 .4 \mathrm{kWh} / \mathrm{kg}$ of produced aluminum. Cooling panels in the side walls of the electrolysis cells were proposed by Aune et al. [2] for improved process control, as well as for high temperature heat recovery. The panels were specified to utilize evaporation and condensation of a working fluid and the recovered heat can be used for, for instance, electricity production. The temperature of the recovered heat depends on the position of the cooling panels in the side-linings of the cells; in the current study, a position corresponding to a temperature range $400-650{ }^{\circ} \mathrm{C}$ was specified. The main components of the electrolyte bath are cryolite $\left(\mathrm{Na}_{3} \mathrm{AlF}_{6}\right)$ and alumina $\left(\mathrm{Al}_{2} \mathrm{O}_{3}\right)$ [1]. The melting point of aluminum is $660{ }^{\circ} \mathrm{C}$, but the cryolite (in which the alumina is dissolved) requires a temperature of $1010^{\circ} \mathrm{C}$ for melting [1]. The electrolyte bath is very corrosive, but with a working temperature of $400-650^{\circ} \mathrm{C}$ in the cooling panels it is possible to create and maintain a protective frozen ledge on the inside of the cell walls. Figure 1 shows a sketch of the cross section of an electrolysis cell equipped with a wall cooling panel [2] (only a part of the cell is shown). The captions in Figure 1 are listed in Table 1. The protective frozen side ledge (24) is formed on the cooling panel. The panel can be exposed to hot spots if the protective frozen side ledge breaks 
down. In such cases, the hot molten electrolyte (12) can come directly in contact with the cooling panel evaporator (8), through cracks in the frozen side ledge. The cooling panel represents the first stage in a heat recovery system, in which heat is transferred from the cooling panel evaporator (8) via the condenser (9) to a cooling circuit (10C) by evaporation and condensation of a working fluid.

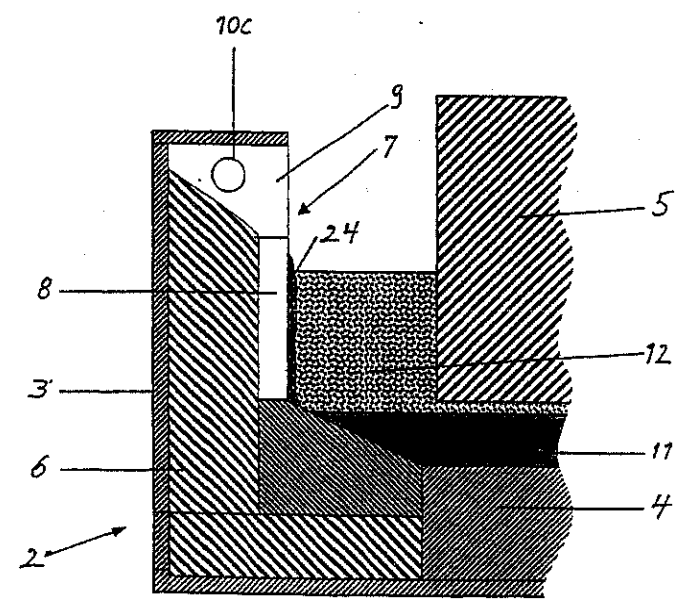

Figure 1. A cross-section of an electrolysis cell with cooling panel [2].

Table 1. Captions in Figure 1.

\begin{tabular}{cc}
\hline Number & Explanation \\
\hline 2 & Electrolysis cell \\
3 & Steel shell \\
4 & Cathode \\
5 & Anode \\
6 & Insulation \\
7 & Cooling panel \\
8 & Cooling panel evaporator \\
9 & Cooling panel condenser \\
$10 \mathrm{C}$ & Cooling circuit \\
11 & Aluminum \\
12 & Electrolyte bath of alumina $\left(\mathrm{Al}_{2} \mathrm{O}_{3}\right)$ and cryolite \\
24 & Solid electrolyte (frozen side ledge) \\
\hline
\end{tabular}

The current paper reports:

- A vertical flat heat pipe considered for use as cooling panel;

- Experimental results obtained for the built heat pipe, in a laboratory test rig;

- A thermal resistance network for the built heat pipe;

- Results from an analytical spreadsheet model of the built heat pipe;

- A numerical study of the thermal expansion of the heat pipe, using finite-element (FEM) analysis; and

- A numerical hot spot analysis, undertaken to determine the most vulnerable position(s) of hot spots on a vertical flat heat pipe wick.

Heat pipes of many forms and for many applications have been proposed and are analyzed in textbooks (for instance, [3-6]); a review including recent advances was given recently by Faghri [7]. In some areas, for instance computer cooling, heat pipe technology is well established; however, due to new areas of application for heat pipes the components, materials, and physical processes of heat pipes are still receiving considerable attention. Reay and Harvey [8] recently reviewed the role of heat pipes in intensified unit operations, and pointed specifically at chemical reactors as highly relevant 
application areas. Heat pipe technology is in the current study considered for the cooling panels of the aluminum electrolysis cells.

In traditional "capillary heat pipes" the inner surfaces of the evaporator, the condenser, and the adiabatic section are all covered by a wick material, or have grooves serving as capillary pumps, wetting the surface. The capillary pressure is the driving force for the flow and distribution of the working fluid in the wick/groove, and in many cases the performance of the wick/groove will be the main limiting factor of the heat pipe. Wicks are still being developed and improved in order to best fit the application requirements. For instance, advanced bimodal wicks have been designed by sintering fine wick structures to coarse wick structures [9]. Another advanced wick has a graded structure which reflects the pressure gradient inside the heat pipe [10]. Several references on wicks of sintered, groove and mesh type were listed in a recent review by Chan et al. [11]. Faghri [3] divided wicks into two groups; homogeneous and composite, and stated that homogeneous wicks are usually chosen due to simple design, manufacture, and installation (i.e., lower costs), even though the composite wicks usually have better performance. Wicks can be made of compressed nickel foam, and the development and testing of such wicks were reported in an earlier paper [12]. This type of wick has the advantage that the wick properties can be selected within a wide range by choosing the degree of compression [13].

Heat pipe wicks are characterized by their porosity, permeability, thermal conductivity, and effective pore radius with regard to a specific fluid. The wick porosity and permeability are properties of the pore structure only [14], independent of the fluid applied. The effective pore radius depends on the contact angle between the wick structure and the fluid applied and is, therefore, not fluid independent. The porosity is usually determined according to a standardized procedure [15]. Various methods exist for the determination of the permeability and the effective pore radius, and in most cases these properties are determined by use of a model fluid and without exposing the wick to a heat flux, for instance as in [16]. Shirazy and Fréchette [17] recently questioned the validity of the effective pore radius determined this way for the calculation of the wick heat transfer capacity (the capillary limit). They had experienced that wicks made of copper foam performed much better in heat pipes than predicted from existing correlations for the capillary limit. Their explanation was that the effective pore radius will decrease during evaporation due to meniscus recession, and thereby increase the wick heat transfer capacity (compared to the value calculated from an effective pore radius determined from an experiment in which the wick was not exposed to heat). More studies of this hypothesis and comparative studies between the different methods for the determination of the permeability and the effective pore radius will increase the reliability of wick heat transfer capacity predictions.

With regard to working fluid, attention is here given to the alkali metal potassium, which is a commonly-used working fluid in traditional heat pipes for the temperature range $500-1000{ }^{\circ} \mathrm{C}[4,7]$. Alkali metals are very reactive, but excellent working fluids in heat pipes when treated correctly. Potassium has to be handled in a high-quality glove box filled with inert gas (such as Ar), or under vacuum, due to the reactivity with oxygen and water (moisture). Hydrogen gas will be produced in the reaction between potassium and water. Potassium will also tend to remove oxide from the surface of steel [18]. Chemical compatibility between the envelope material and the working fluid is essential in order to avoid corrosion and/or inert gas generation. Ten years of successful operation was reported for a heat pipe made of stainless steel 718 envelope and 316L wick material, utilizing sodium as a working fluid at $750{ }^{\circ} \mathrm{C}$ operating temperature [19]. In industry, lifetimes of years are usually needed and expected for heat pipes, often with harsh thermal, chemical, and mechanical loads. Compatibility between the heat pipe and its surroundings is, therefore, equally important to the internal compatibility between the envelope, wick, and working fluid. Metals are the dominating envelope and wick materials, but high temperature wickless heat pipes (thermosyphons) of ceramic material are also being developed; results from promising experiments with sodium and zinc as working fluids were reported recently [20]. Nickel is compatible with potassium [4], but starts oxidizing rapidly at about $350{ }^{\circ} \mathrm{C}$ [21] and a protective/reducing gas atmosphere of $5 \%(\mathrm{v}) \mathrm{H}_{2}, 95 \%(\mathrm{v}) \mathrm{Ar}$ is therefore often used 
during the heat treatments and preparations of the nickel wicks and heat pipe envelopes. Stainless steel 304 is also reported to be compatible with potassium [4], and may be a more economical choice than nickel for heat pipes for industrial applications.

Panels/heat pipes in the side lining of the aluminum electrolysis cells should be as slim as possible. Attention must, therefore, be given to the sonic limit for the vapor flow, especially when alkali metal working fluids are applied, due to their low vapor densities [22]. The entrainment and flooding limits will also be important if the vapor and condensate are in direct contact and flowing in opposite directions in a heat pipe/thermosyphon.

\section{Experimental Characterization}

An experimental study was carried out to investigate the performance of a flat vertical heat pipe under temperature and heat flux conditions expected in the walls of aluminum electrolysis cells (including hot spot heat fluxes). The hypothesis was that a wick in the evaporator section would be a robust solution for the distribution of working fluid over the evaporator surface under varying temperature and heat flux conditions.

\section{The Heat Pipe}

An experimental heat pipe was made specifically for this study. The built experimental heat pipe is shown in Figure 2, to the left fully assembled, to the right split in two.
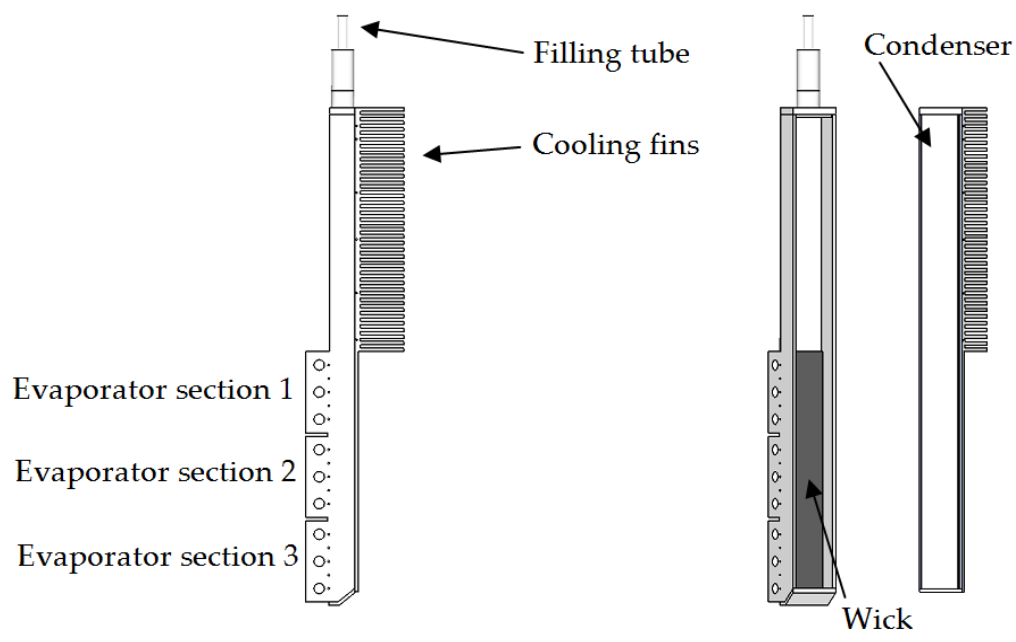

Figure 2. The experimental heat pipe fully assembled (left) and split in two (right).

For the current experimental study, nickel was selected both for the envelope and the wick, due to its relatively high thermal conductivity and reported compatibility with potassium. The heat pipe was designed "as slim as possible", according to the requirements for the cooling panel for electrolysis cell walls. However, the dimensions of the flow channel were chosen such that the sonic limit, the entrainment limit, and the flooding limit were unlikely to cause problems. Correlations available in reference $[3,4]$ for predicting these limits were used in the design process. The flow channel width was chosen so large that the sidewalls of the heat pipe would likely not cause significant disturbance of the fluid flow.

The experimental heat pipe had no adiabatic section, due to manufacturing limitations. The total height of the evaporator was $150 \mathrm{~mm}$. The inner height of the condenser section was $142 \mathrm{~mm}$. The inner width of the flow channel was $25 \mathrm{~mm}$ and the depth $11.55 \mathrm{~mm}$. A wick, $25 \mathrm{~mm} \times 150 \mathrm{~mm} \times 1.15 \mathrm{~mm}$, consisting of four layers of compressed and sintered nickel foam was attached to the evaporator surface by use of electron beam spot welding. The evaporator was divided in three sections where each had three cartridge heaters. The motivation for having multiple sections was to be able to 
impose a non-uniform heat flux distributions over the evaporator surface. The cartridge heaters were mounted into the heat pipe having force fit tolerances, hence no thermal paste was necessary. The supplied power to each evaporator section was controlled by phase angle firing thyristors. Each cartridge heater was rated $225 \mathrm{~W}$ at $240 \mathrm{~V}$, and had a maximum work temperature of $760{ }^{\circ} \mathrm{C}$. For an ideal case without heat losses the nine cartridge heaters could, from their specifications, provide a maximum uniform heat flux of $540 \mathrm{~kW} / \mathrm{m}^{2}$. The temperatures in the evaporator wall were measured by $3 \times 5$ type $\mathrm{N}$ thermocouples, $\varnothing 1 \mathrm{~mm}$, installed in pockets in each section of the evaporator wall. Similar thermocouples were also installed in pockets in the condenser wall and on the outside of the heat pipe adiabatic walls (the walls opposite of the evaporator, respective condenser surfaces). LabView $^{\circledR}$ together with modules NI 9214, NI 9219, NI 9225, and NI 9227 from National Instruments ${ }^{\circledR}$ were used for data recording and parameter control. The uncertainty of the measurement of the power supplied to the cartridge heaters was less than $1 \%$. The thermocouples attached to the logging system were calibrated by use of a JOFRA RTC-700 calibrator (accuracy $\pm 0.11 \mathrm{~K}$ ). The amount of potassium filled into the heat pipe was $10.2 \mathrm{~g}$, which was estimated to be sufficient for full wetting of the wick, with a good safety margin, for all planned experimental operating conditions.

The outside of the condenser section was equipped with fins and was cooled by nitrogen gas. The heat taken up by the nitrogen gas was calculated from the measured nitrogen flow rate and the temperature increase of the nitrogen over the condenser $\left(Q_{N_{2}}=\dot{m}_{N_{2}} \cdot c_{p, N_{2}} \cdot \Delta T_{N_{2}}\right)$. The inlet temperature of the nitrogen was kept at $50{ }^{\circ} \mathrm{C}$. The nitrogen flow rate was determined from the volume flow rate measured by use of a Sierra $620 \mathrm{~S}$ insertion flow meter in the cooling circuit. The range of the Sierra flow meter was $0-23.45 \mathrm{Nm}^{3} / \mathrm{h}$ and the uncertainty $\pm 0.28 \%=0.066 \mathrm{Nm}^{3} / \mathrm{h}$, where $\mathrm{N}$ in this particular case was defined as $15^{\circ} \mathrm{C}$ and $1 \mathrm{~atm}$. The heat loss to the surroundings was the difference between the heat supplied to the heat pipe by the cartridge heaters and the heat taken up by the nitrogen gas. For safety reasons, the heat pipe was in a container filled with nitrogen gas during the experiments.

\section{Theoretical Analysis}

\subsection{Wick Performance}

The limitation that directly addresses the performance of the wick alone is defined by the pressure balance [3]:

$$
\Delta P_{c a p, \max } \geqslant \Delta P_{h s}+\Delta P_{f}
$$

The pressure loss of the vapor flow in the heat pipe is not taken into account here, as attention is given to the wick only. Inertia effects in the wick and the pressure losses associated with the interfacial thermal resistances are also omitted because these terms are small compared to the terms of Equation (1) in the current case.

If the tortuous flow paths in the wick are represented by a capillary tube model then the capillary pressure can be expressed from the Young-Laplace equation as:

$$
\Delta P_{c a p, \max }=\frac{2 \sigma}{r_{e f f}}
$$

The hydrostatic pressure of the working fluid in the wick relative to the vapor pressure outside the wick is:

$$
\Delta P_{h s}=\rho_{l} g H
$$

The frictional pressure loss due to the flow of working fluid in the wick is calculated by use of Darcy's law:

$$
\Delta P_{f}=\frac{\mu_{l}}{\kappa A_{c} \rho_{l}} \int_{0}^{H} \dot{m}_{l} d y
$$


The total heat transfer capacity (in Watts) of a vertical flat wick exposed to a uniform heat flux is obtained by inserting Equations (2)-(4) into Equation (1) [12]:

$$
Q=\dot{m}_{l, \max } \cdot h_{f g}=\frac{2 \kappa A_{c} \rho_{l}}{H \mu_{l}}\left(\frac{2 \sigma}{r_{e f f}}-\rho_{l g} H\right) h_{f g}
$$

Equation (5) has been applied to predict the heat transfer capacity of the wick in the capillary pressure-limited range. In the vapor static pressure-limited range the capillary pressure term $\left(2 \sigma / r_{e f f}\right)$ in Equation (5) is replaced by the vapor pressure of the working fluid [21].

\subsection{The Numerical Hot Spot Analysis}

A numerical 2D hot spot analysis for a flat vertical wick was carried out, considering the combined effect of frictional and static pressure losses due to localized regions of high heat flux. The method is quite similar to the method described in [23]. The relevant equations were discretized and solved numerically using MatLab ${ }^{\circledR}$.

Starting with the continuity equation:

$$
\frac{\partial u}{\partial x}+\frac{\partial v}{\partial y}=\frac{\alpha}{\rho}
$$

where $\alpha=f(x, y)$ is a mass flux source/sink function, and expressing the velocity components $u$ and $v$ respectively using Darcy's law:

$$
u=-\frac{\kappa}{\mu} \frac{\partial P}{\partial x} \quad ; \quad v=-\frac{\kappa}{\mu} \frac{\partial P}{\partial y}
$$

Equation (7), inserted into the continuity equation, Equation (6), yields Equation (8) which describes the pressure field due to flow friction in the wick:

$$
\frac{\partial^{2} P}{\partial x^{2}}+\frac{\partial^{2} P}{\partial y^{2}}=-\frac{\mu \alpha}{\rho \kappa}
$$

Appropriate boundary conditions are:

Through the left and right boundaries there is no flow, i.e.,:

$$
\left(\frac{\partial P}{\partial x}\right)_{\text {right,left boundary }}=0
$$

No flow through the top boundary, i.e.,:

$$
\left(\frac{\partial P}{\partial y}\right)_{\text {top boundary }}=0
$$

At the bottom of the wick the following boundary condition applies:

$$
P_{\text {bottom }}=P_{\text {sat }}-\rho g H
$$

where the hydrostatic pressure as a function of height from the liquid bath, $y$, is:

$$
P_{\text {hydrostatic }}=\rho g y
$$

$H$ is the height of the wick. It should be emphasized that this definition of $P_{\text {bottom }}$ is a fictive pressure, created as an intermediate step in the calculation, the real pressure at the bottom of the wick is $P_{\text {sat }}$. The boundary condition $P_{\text {bottom }}$ as defined by Equation (11) may be seen as the pressure available to overcome flow friction. 
The total pressure field in the vertical wick is:

$$
P_{\text {total }}(x, y)=P_{\text {flow friction }}(x, y)+P_{\text {hydrostatic }}(y)
$$

The total pressure is compared to a critical pressure, which may be seen as the "pressure remaining in the wick" and has minimum values defined by Equations (14) and (15):

$$
\begin{gathered}
P_{\text {critical }}=\left(P_{\text {sat }}-\frac{2 \sigma}{r_{e f f}}\right) \text { when } P_{\text {sat }}>\frac{2 \sigma}{r_{e f f}} \\
P_{\text {critical }}=0 \text { when } P_{\text {sat }}\left\langle\frac{2 \sigma}{r_{e f f}}\right.
\end{gathered}
$$

The calculation procedure is as follows:

1. The pressure field in the wick is calculated from Equation (8) and the boundary conditions, i.e., the pressure field is determined entirely by the flow friction, starting from the saturation pressure minus the hydrostatic pressure at the bottom of the wick.

2. The total pressure field in the wick is then calculated by adding the hydrostatic pressure, as a function of height $y$, to the pressure field generated in point 1, according to Equation (13).

3. For the selected heat fluxes and hot spot the minimum pressure in the total pressure field is compared to the critical pressure defined by Equation (14) or Equation (15). The wick works well if the minimum total pressure is higher than the critical pressure. The capacity of the wick has been exceeded if the minimum total pressure is lower than the critical pressure.

\subsection{Thermal Resistance Model for the Whole Heat Pipe}

The thermal resistance network for the heat pipe is shown in Figure 3. Heat is supplied from the cartridge heaters at the lower left of the resistance network. The heat leaves the network with the nitrogen gas to the right or as heat loss to the left.

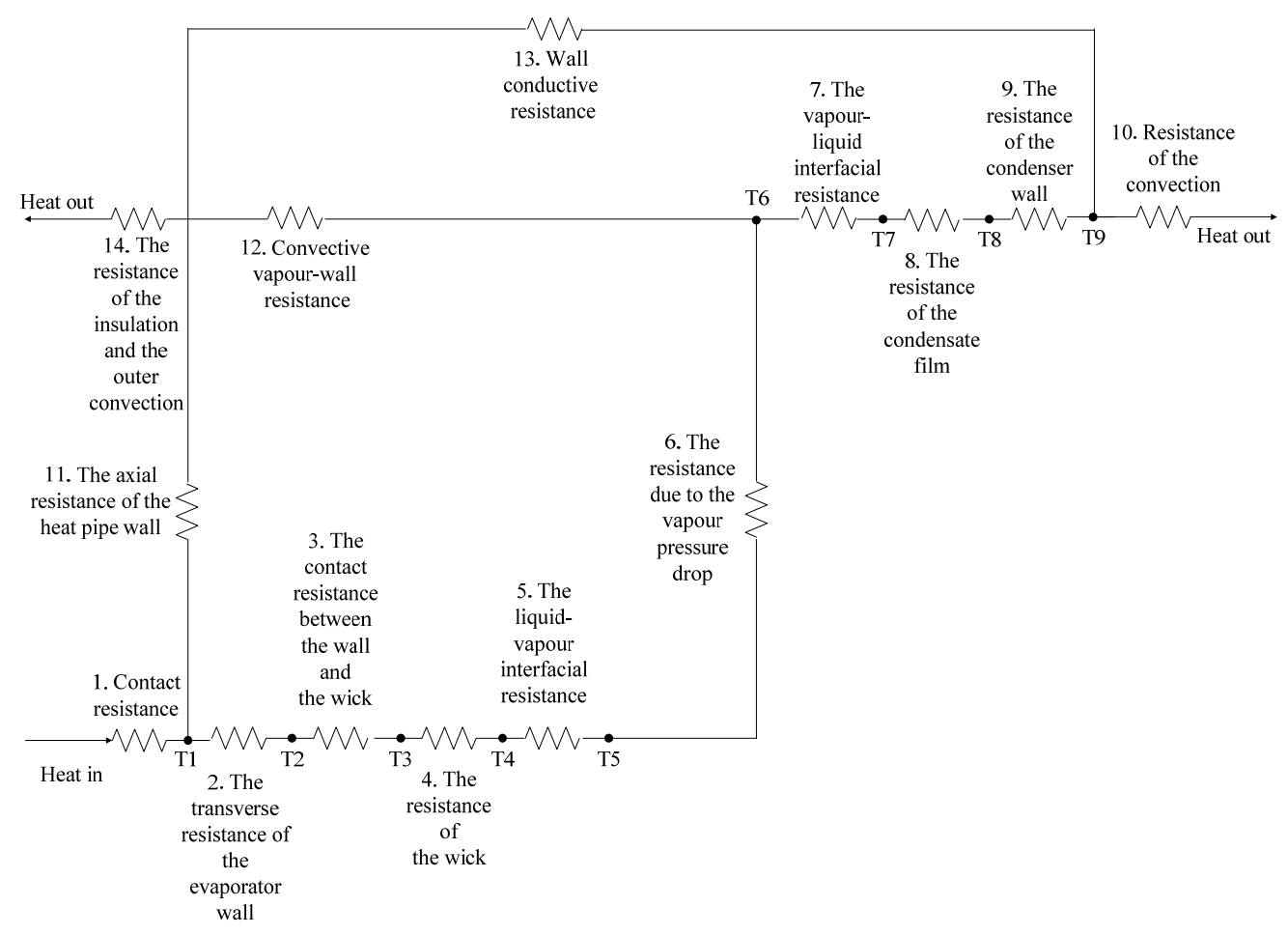

Figure 3. The thermal resistance network of the heat pipe. 
A simplified model of the heat pipe based on major heat transfer resistances was developed and implemented in a spreadsheet. With known dimensions and boundary conditions, the individual resistances in Table 2 were calculated. This process was iterative, as the operating condition in the heat pipe had to be determined. For simplicity, metal/metal thermal contact resistances were neglected, as were axial conduction in the heat pipe wall, resistance due to vapor pressure loss, and blowing and suction effects in the evaporator and condenser. The heat transfer coefficient for the nitrogen convective gas cooling, $h_{\text {convection, }}$, was calculated for flow in a rectangular channel because, when mounted in the test rig, the flow areas between the heat pipe fins became rectangular channels. Fully developed flow was assumed, which gave a conservative estimate for $h_{\text {convection }}$. A fin efficiency was calculated to account for the temperature gradient in the fins. The magnitudes of the thermal resistances listed in Table 2 are compared in the Results and Discussion section. The spreadsheet model was also used to estimate the operating temperature $\left(T_{5}\right.$ in Figure 3$)$ of the heat pipe for the following input parameters: heat input, nitrogen gas flow rate, and inlet temperature. Operating temperatures calculated by use of the spreadsheet model have been compared to measured operating temperatures in the Results and Discussion section. With regard to uncertainty, the input parameters are based on the measurements and have the same uncertainties as them. The output parameters have, in addition, the uncertainties from the different resistances in the network plus the uncertainty of the simplifications, which are not quantified.

Table 2. Thermal resistances taken into account.

\begin{tabular}{|c|c|c|}
\hline Thermal Resistance & Expression for $R^{\prime \prime}\left(\left(\mathrm{m}^{2} \cdot \mathrm{K}\right) / \mathrm{W}\right)$ & Reference \\
\hline $\begin{array}{l}\text { 2. The transverse resistance } \\
\text { of the evaporator wall. }\end{array}$ & $\frac{L}{k_{N i 201}}$ & {$[24]$} \\
\hline 4. The resistance of the wick. & $\frac{2 L}{\left[(1-\varepsilon) k_{\text {solid }}+\varepsilon k_{\text {fluid }}\right]+\left[\frac{k_{\text {fluid }} \cdot k_{\text {solid }}}{\varepsilon k_{\text {solid }}+k_{\text {fluid }}(1-\varepsilon)}\right.}$ & $\begin{array}{c}\text { The average of parallel and } \\
\text { serial wick resistances [3] } \\
\text { was assumed. }\end{array}$ \\
\hline $\begin{array}{l}\text { 5. and } 7 \text {. The liquid-vapor } \\
\text { and vapor-liquid interfacial } \\
\text { resistance. }\end{array}$ & $\frac{1}{\left(\frac{2 \alpha}{2-\alpha}\right)\left(\frac{h_{f g}^{2}}{T_{v} v_{f g}}\right) \sqrt{\frac{M_{v}}{2 \pi R_{u} T_{v}}}\left(1-\frac{p_{v} v_{f g}}{2 h_{f g}}\right)}$ & [3] \\
\hline $\begin{array}{l}\text { 8. The resistance of the } \\
\text { condensate film. }\end{array}$ & $\frac{\left(\frac{3 \mu_{l} \Gamma}{g \rho_{l}\left(\rho_{l}-\rho_{v}\right)}\right)^{\left(\frac{\overline{3}}{3}\right)}}{k_{l}}$ & [24] \\
\hline $\begin{array}{l}\text { 9. The resistance of the } \\
\text { condenser wall. }\end{array}$ & $\frac{L_{\text {wall }}}{k_{\text {Ni201 }}}$ & [24] \\
\hline $\begin{array}{l}\text { 10. Resistance of the nitrogen } \\
\text { gas convective cooling. }\end{array}$ & $\frac{1}{h_{\text {convection }}}$ & [24] \\
\hline
\end{tabular}

\section{Results and Discussion}

\subsection{Thermal Resistance Model}

Using the developed model, the magnitudes of the heat pipe related thermal resistances were calculated and are compared in Figure 4 for an operating temperature of about $500{ }^{\circ} \mathrm{C}$. The thermal resistance on the coolant side has been omitted in Figure 4 as this resistance depends on the cooling fluid (in this case $\mathrm{N}_{2}$-gas) and is not related to the heat pipe characteristics (for the experimental heat pipe setup, the coolant-side resistance represented $85 \%$ of the total resistance due to the poor heat transfer characteristics of the nitrogen gas). Figure 4 shows the relative magnitudes of the resistances associated with the heat pipe, for $2 \mathrm{~mm}$ envelope wall thickness overall. The thermal resistances associated with the conduction through the evaporator and condenser walls were the largest, followed by the thermal resistance of the wick, the interfacial resistances, and finally the thermal resistance of 
the condensate film. The interfacial thermal resistance at the vapor/liquid interface was about twice the thermal resistance of the condensate film, which emphasizes that interfacial thermal resistances can be important in studies of metal vapor condensation [25]. The magnitude and relative importance of the interphase thermal resistances increase with decreasing temperature; however, at an operating temperature of $500{ }^{\circ} \mathrm{C}$ the thermal resistances associated with the condensation of the potassium constitute only a small part of the total thermal resistance. The total thermal resistance between the evaporator and condenser external surfaces is $0.031 \mathrm{~K} / \mathrm{W}$, representing an effective axial thermal conductivity of the heat pipe of $10,560 \mathrm{~W} /(\mathrm{m} \cdot \mathrm{K})$ for an effective length of $14.6 \mathrm{~cm}$ and an outer axial cross-sectional area of $451 \times 10^{-6} \mathrm{~m}^{2}$. For comparison, this represents a thermal conductivity of 26.4 times the thermal conductivity of copper $(400 \mathrm{~W} /(\mathrm{m} \cdot \mathrm{K})[24])$.

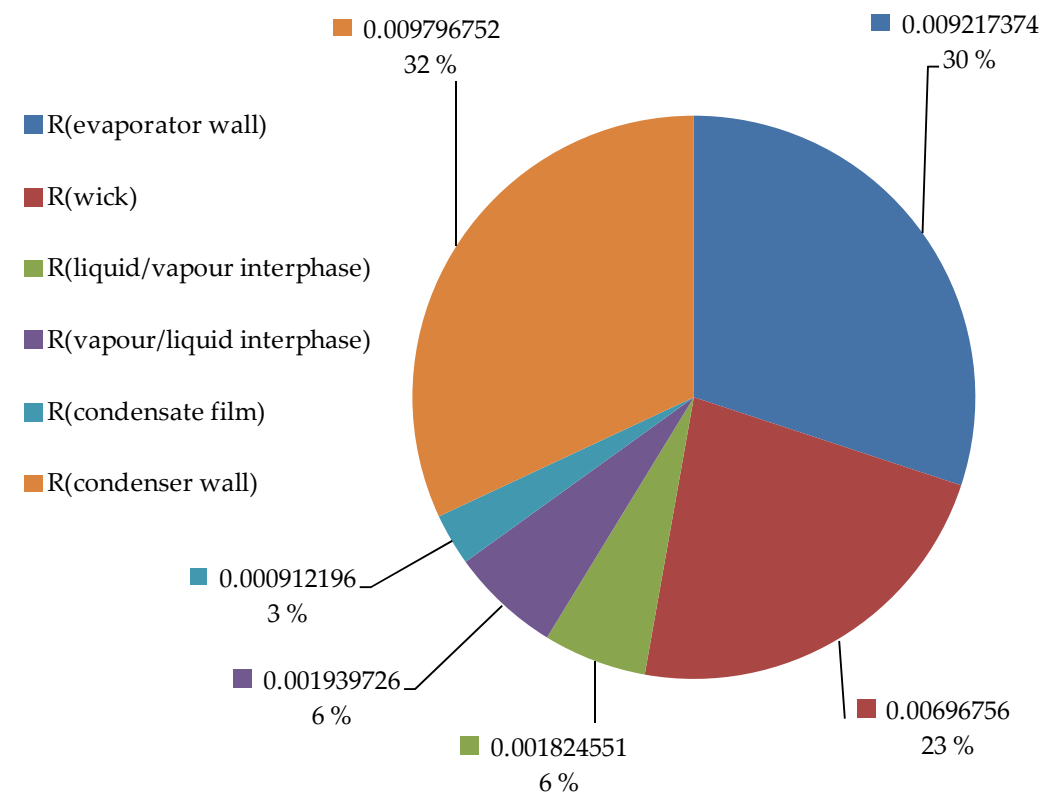

Figure 4. The importance of the considered thermal resistances $[\mathrm{K} / \mathrm{W}]$ at $T_{5} \approx 500{ }^{\circ} \mathrm{C}$.

In Figure 5 the heat pipe operating temperatures calculated by use of the spreadsheet model are compared to measured operating temperatures.

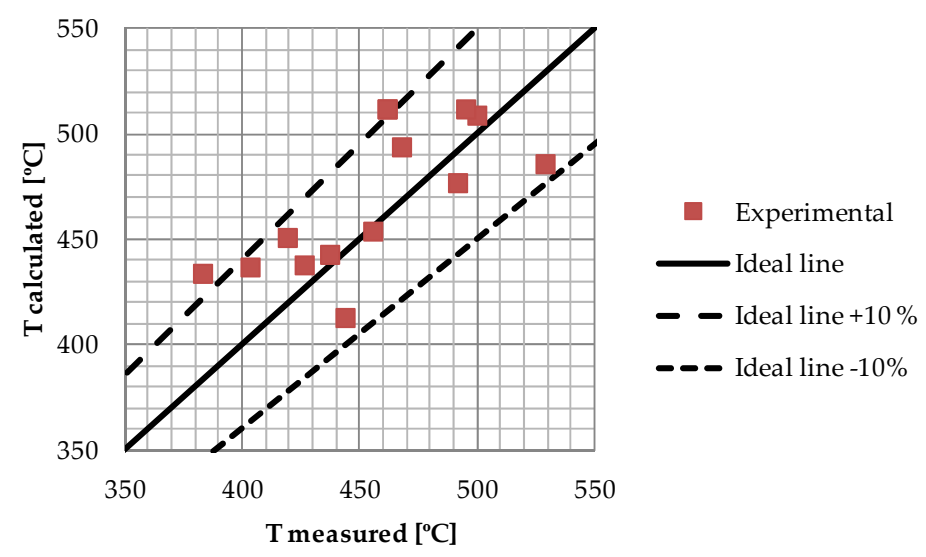

Figure 5. Calculated vs. measured operating temperatures, at position $T_{5}$ (Figure 3).

For the limited set of data comparisons the simplified thermal resistance model seems to reproduce the experiments to within $\pm 10 \%$. The points in Figure 5 were obtained at a wide range of experimental conditions; heat fluxes were in the range from $38 \mathrm{~kW} / \mathrm{m}^{2}$ to $360 \mathrm{~kW} / \mathrm{m}^{2}$ and $\mathrm{N}_{2}$ flow rates between 
$2.3 \mathrm{Nm}^{3} / \mathrm{h}$ and $17.2 \mathrm{Nm}^{3} / \mathrm{h}$. The main reason for the prediction deviation is related to transient heat losses to the insulation and safety chamber not fully accounted for in the spreadsheet model.

\subsection{Performance Limitations of the Wick, Analytical, and Experimental Results}

The capillary pressure in a heat pipe wick can never be higher than the vapor pressure of the working fluid. This will limit the performance of the heat pipe wick, as it is the capillary pressure (or the vapor static pressure) that will be the "driving force" in Equation (5).

The active height of the heat pipe wick was $11.2 \mathrm{~cm}$, and the wick capacity limitations are shown in Figure 6.

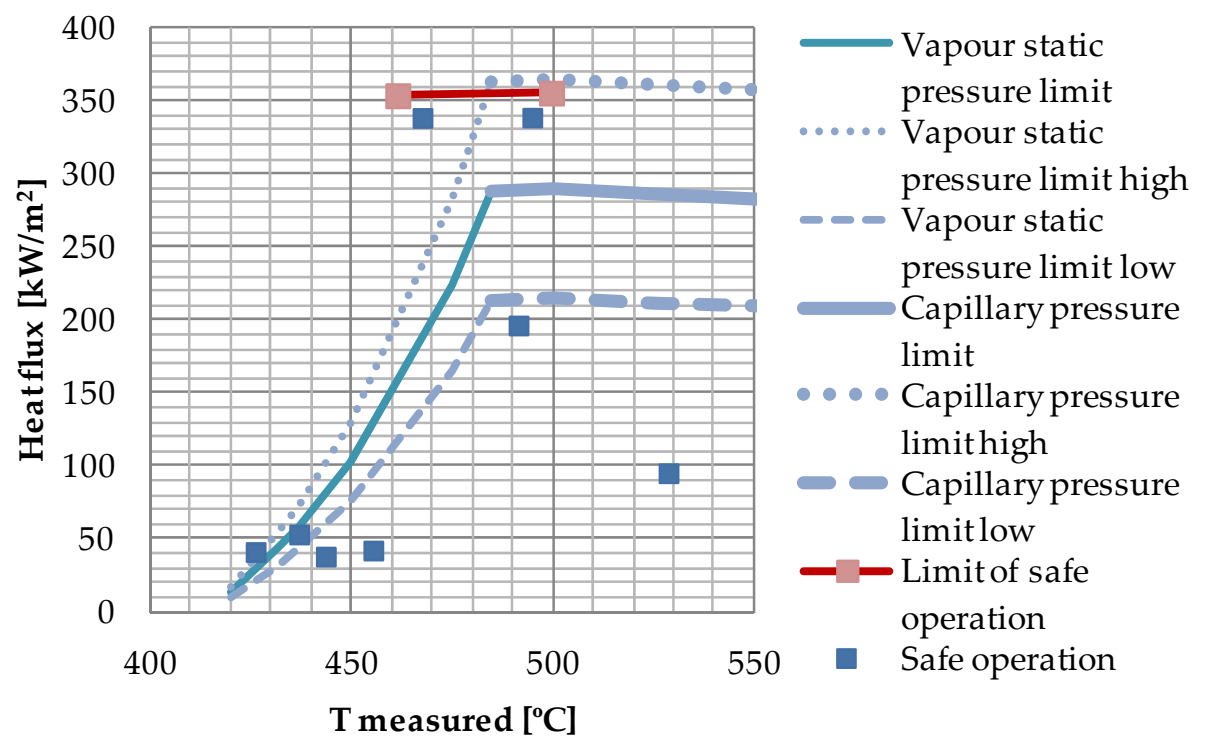

Figure 6. Wick performance data for wick height $11.2 \mathrm{~cm}$. Dots represent experimental data. Red dots—at maximum performance limit; blue dots—safe operation.

For a uniform heat flux the dryout at the exceedance of the wick maximum capacity would be expected to occur at the top of the wick, i.e., an accompanying temperature peak would be registered at the top of evaporator Section 1 in Figure 2. For the experiments reported in Figure 6 the heat flux was increased in small steps, and the temperatures in the evaporator were monitored graphically on the computer screen. For heat fluxes above the reported measured limits the rapid increase in temperature did not occur at the top of the wick, but at the top of evaporator Section 2. This could indicate that the evaporator surface dryout and the accompanying temperature peak were caused by a local contact problem between the wick and the evaporator surface at the top of evaporator Section 2, rather than by the exceedance of the "pumping" capacity of the wick. In such case, the maximum capacity of the wick could be even higher than shown by the experimental points in Figure 6 . The most likely scenario is that such a contact problem was caused by thermal expansions, which are largest at the maximum heat flux. In the following discussion it is assumed that the measured maximum reported in Figure 6 represents the maximum capacity of the $11.2 \mathrm{~cm}$ wick, even though the dryout did not occur at the top.

From Figure 6 it is observed that the heat pipe was able to operate above the vapor static pressure limitation calculated for the whole effective wick height $(11.2 \mathrm{~cm})$, while in the capillary pressure limited range the performance overlapped the calculated limit when the experimental uncertainty was taken into account. The large uncertainty indicated in Figure 6 by the high and low vapor static pressure limit curves and the high and low capillary pressure limit curves is a result of the uncertainty of the permeability of the compressed wick, which was calculated to $\pm 26 \%$ [12]. In general, from Equation (5), the heat transfer capacity will increase by decreased effective pore radius and/or increased permeability. Increased effective pore radius due to a heat flux, as described by Shirazy and 
Fréchette [17], will only have effect in the capillary pressure limited region. The experimental point above the vapor static pressure limit line can, therefore, only be explained if the real permeability of the wick was higher than the value $\left(73 \times 10^{-12} \mathrm{~m}^{2}\right)$ used in the calculation of the corresponding limit. However, the calculated limits are extremely sensitive to the permeability. Estimates have shown that a small channel in the wick, or between the heated wall and the wick, in the order of $34 \mu \mathrm{m}$, will increase the permeability sufficiently to explain the deviation between experiments and predictions. It is not unlikely that such a channel can have been created between the compressed foam layers of the wick due to the mechanical handling of the heat pipe, or due to thermal expansion, as discussed in the following.

\subsection{Thermal Expansion}

A heat transfer panel/heat pipe located in the side lining of an aluminum electrolysis cell will be exposed to unilateral heat fluxes. The temperature gradients caused by the unilateral heat flux will cause some thermal deformation for any real structure of finite thermal conductivity, such as the heat pipe envelope. The thermal deformation of the heat pipe was analyzed by use of Comsol Multiphysics ${ }^{\circledR}$. Figure 7 shows the results from one of the most extreme cases, where about $480 \mathrm{~kW} / \mathrm{m}^{2}$ were applied to each of the upper two evaporator sections and about $160 \mathrm{~kW} / \mathrm{m}^{2}$ was applied to the lower evaporator section.

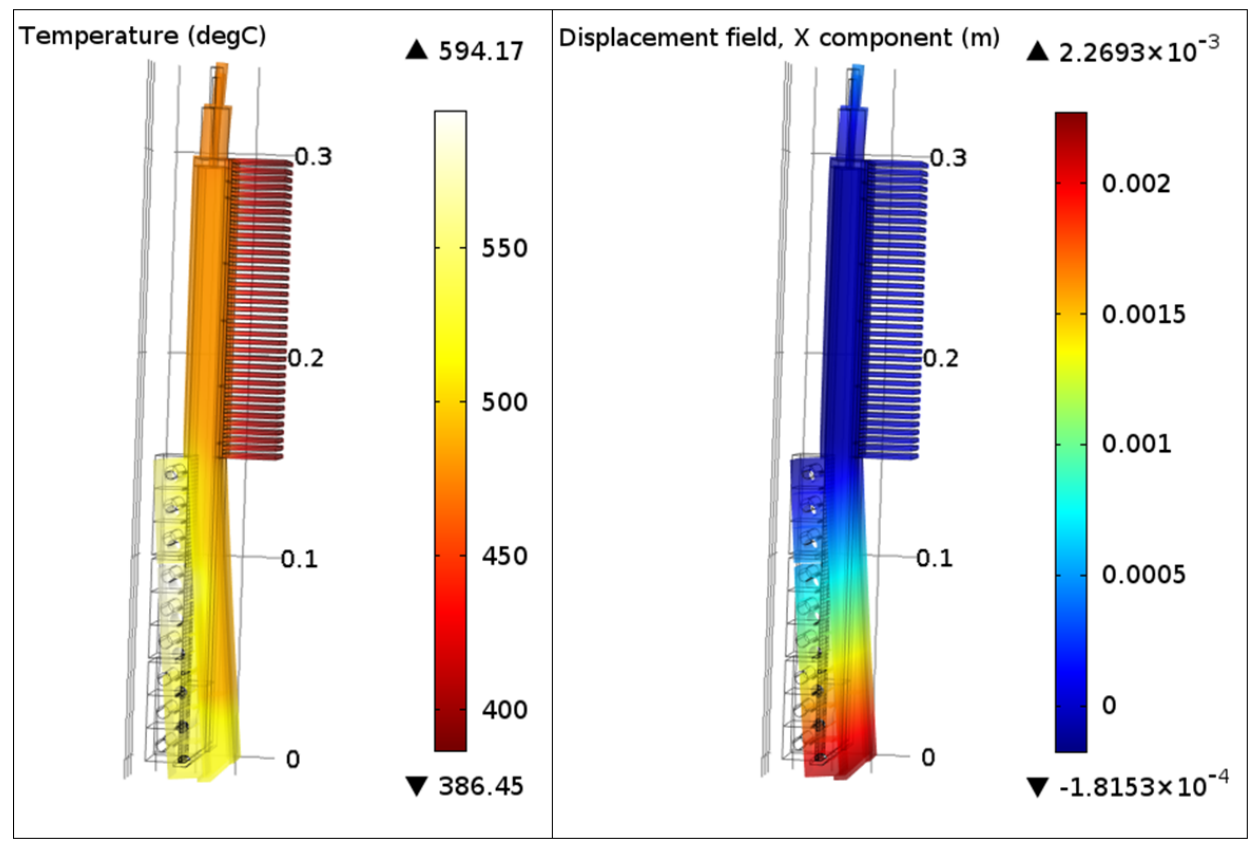

Figure 7. Temperature distribution $\left[{ }^{\circ} \mathrm{C}\right]$ and corresponding thermal deformation $[\mathrm{m}]$ of the heat pipe.

The heat pipe was fixed at the fin base. The results shown in Figure 7 indicate that the heat pipe bends more than 2 millimeters due to the unilateral heat flux, despite the relatively high thermal conductivity of the envelope material (Ni201). Under the current conditions the temperature at the cartridge heaters was about $90 \mathrm{~K}$ above the operating temperature of the heat pipe. Awareness about thermal deformation is important in future design processes in order to implement solutions which can prevent potential thermal contact problems on the outside of the heat pipe, as well as between the wick and the evaporator surface. 


\subsection{Numerical 2D Hot Spot Analysis}

In this section the results of the numerical study of hot spots on vertical flat wicks are reported. Different scenarios were considered, exemplified here by analysis of the consequences of hot spots in the different positions, 1 to 9, of the wick in Figure 8. The maximum uniform heat flux for the whole wick is used as reference in the discussion. Dryout will occur at the top of the wick if the maximum uniform heat flux is exceeded.

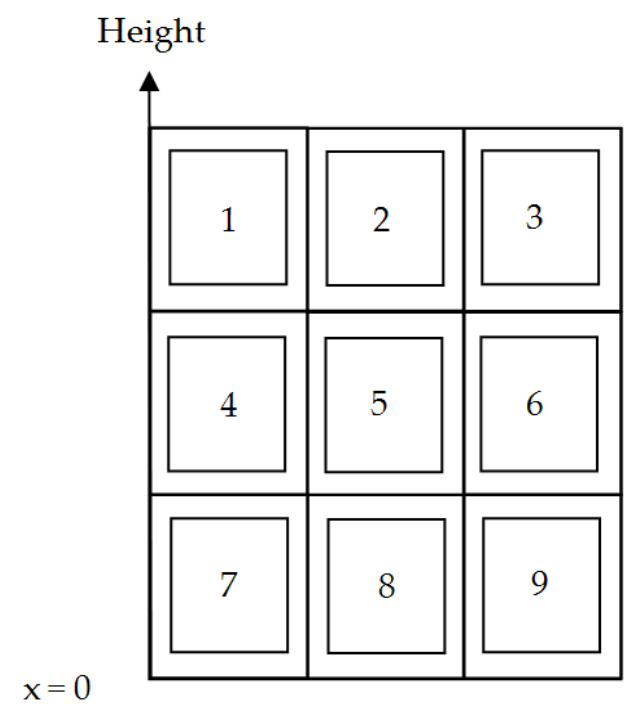

Figure 8. A vertical rectangular wick with nine potential hot spot positions.

The experimental heat pipe wick ( $0.025 \mathrm{~m}$ wide) represented just a slice of a larger wick for a cooling panel. The width of the wick in the numerical study was set to $0.112 \mathrm{~m}$, giving a quadratic wick for this analysis. The size of the hot spot was $0.0112 \mathrm{~m} \times 0.0112 \mathrm{~m}$, i.e., it occupied $1 \%$ of the wick area. The wick properties and thickness were the same as for the experimental wick.

In Figure 9 the pressure field obtained from of one of the numerical calculations is shown. A hot spot of 15 times the normal heat flux has been imposed in position 2, Figure 8, where the normal heat flux is defined as the maximum uniform heat flux outside of the hot spot. The temperature for this case was $773 \mathrm{~K}$, the working fluid potassium, the wick permeability $73 \times 10^{-12} \mathrm{~m}^{2}$ and the effective pore radius $50.8 \times 10^{-6} \mathrm{~m}$. The pressure isolines in the upper part of the wick are clearly affected by the presence of the hot spot. The distance between the $2000 \mathrm{~Pa}$ line and the $1500 \mathrm{~Pa}$ line is smallest at the horizontal position of the hot spot due to the high flow friction pressure drop around the hot spot. In general the vertical distance between the pressure isolines is increasing from the bottom of the wick and up; this is because the mass flow rate in the wick is decreasing upwards due to the evaporation. The minimum pressure $\left(\mathrm{P}_{\text {critical }}=1283 \mathrm{~Pa}\right.$, Equation (14)) is marked with a small circle on the top of the wick, i.e., in this case the dryout occurs at the top of the wick and not in the hot spot.

Figure 10 shows the maximum average heat flux, i.e., $q_{\text {max, average }}=\left(0.99+0.01 \cdot q_{\text {hotspot }} / q_{\text {normal }}\right) q_{\text {normal }}$, for the case $q_{\text {hotspot }} / q_{\text {normal }}=15$ as a function of the position of the hot spot. For a hot spot positioned below the vertical mid-position the average heat flux increases above the nominal value of $301.5 \mathrm{~kW} / \mathrm{m}^{2}$, whereas for positions above the middle the heat flux is lower than the nominal value. 


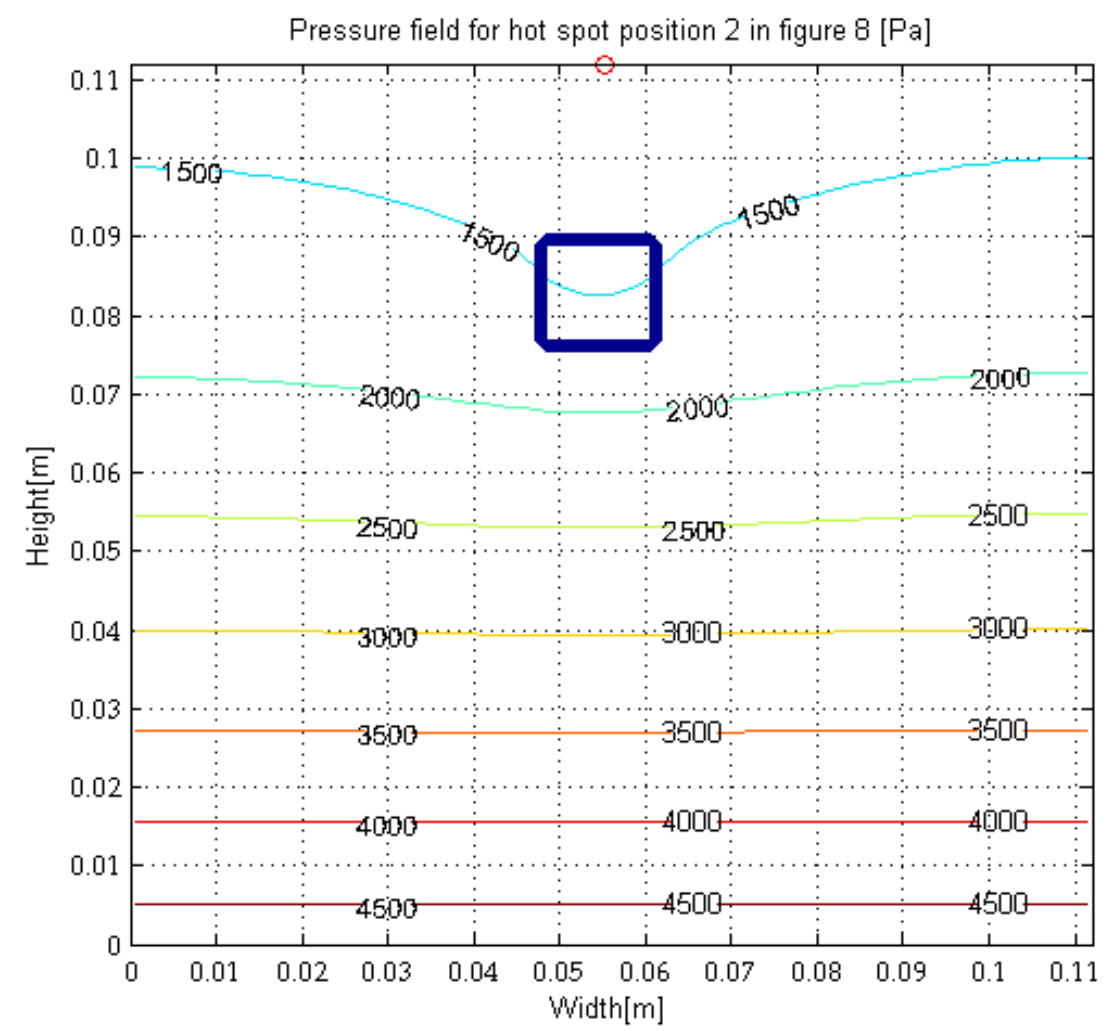

Figure 9. The pressure field for a 0.112 wide and $0.112 \mathrm{~m}$ high wick with a hot $\operatorname{spot}\left(q_{\text {hotspot }} / q_{\text {normal }}=15\right)$.

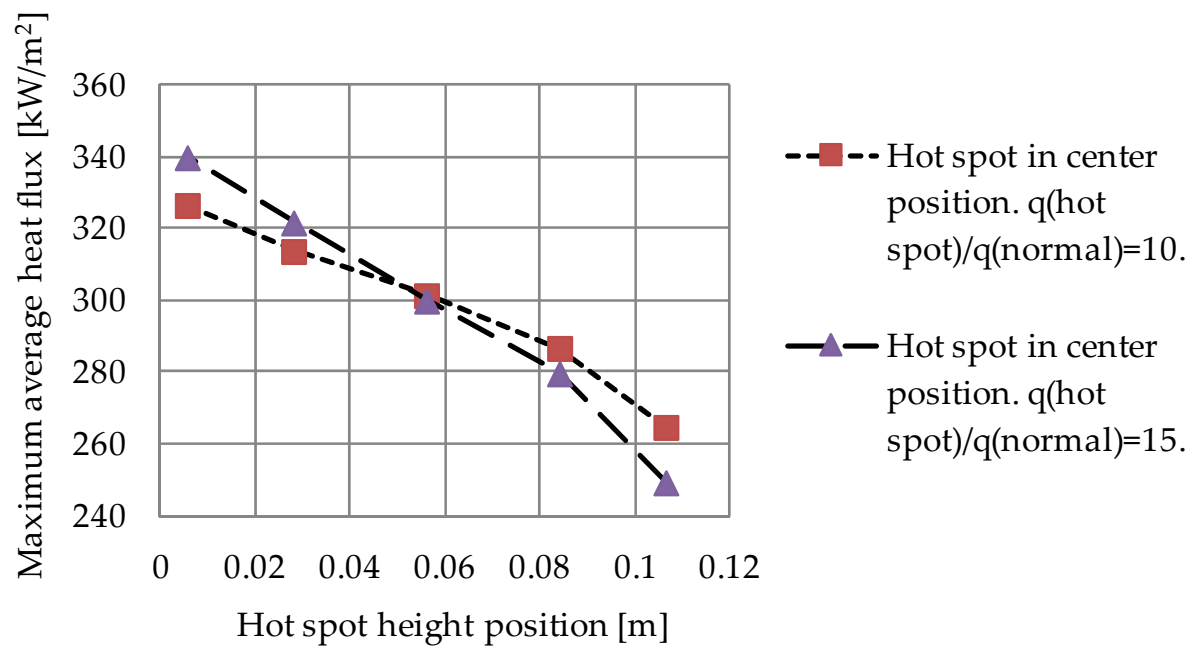

Figure 10. Maximum average heat flux as a function of hot spot vertical position.

Compared to the nominal case $301.5 \mathrm{~kW} / \mathrm{m}^{2}$ (without hot spot) a high flux hot spot above the mid-position will be more detrimental than a weaker hot spot. For a hot spot below the mid-position the reduced flow distance for the supply to the hot spot will be increasingly important with increasing hot spot heat flux.

In Figure 11 the wick maximum average heat flux, $q_{\max , \text { average }}$, has been plotted for cases with hot spots $q_{\text {hotspot }} / q_{\text {normal }}=10$ and $q_{\text {hotspot }} / q_{\text {normal }}=15$ for different horizontal positions at the hot spot center vertical position $(0.112-0.0112 / 2)=0.1064 \mathrm{~m}$. 

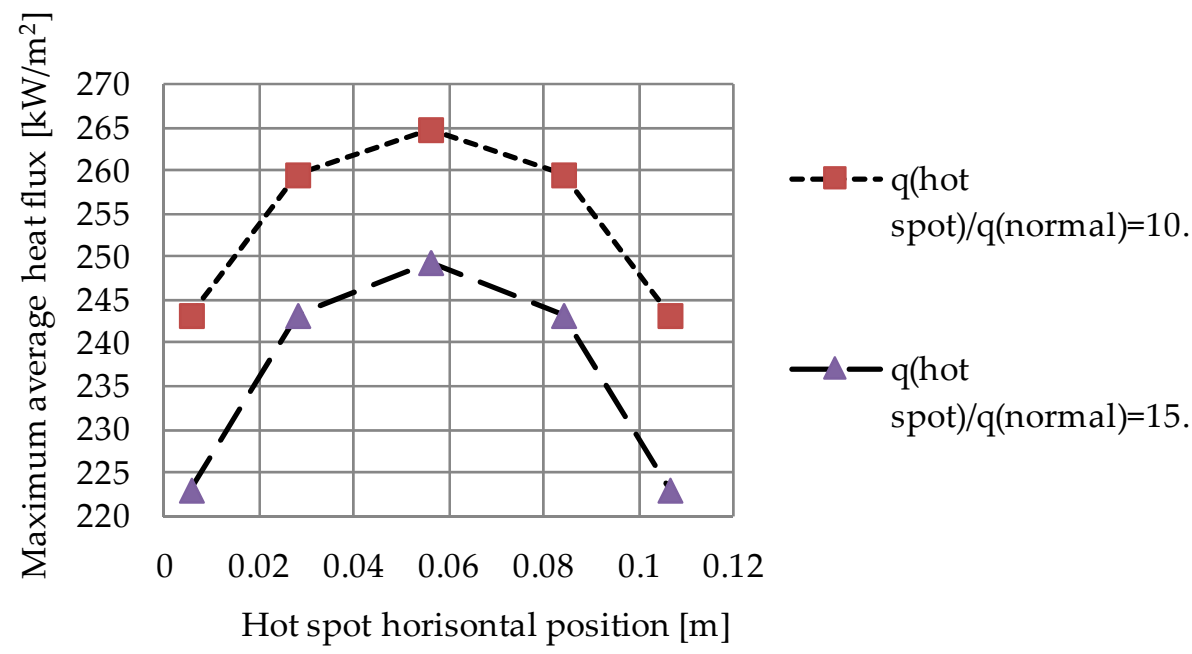

Figure 11. Maximum average heat flux for hot spots at different horizontal positions, all at top height level.

In Figure 11 the least detrimental hot spot positions are at the vertical centerline (i.e., for $0.056 \mathrm{~m}$ horizontal position), where the hot spots can receive liquid symmetrically from both sides. The flow resistance increases with distance from the centerline, and accordingly the maximum average heat flux decreases.

Figures 10 and 11 show that the impact of the hot spot increases with its heat flux and that the vertical position of the hot spot is more important than the horizontal position for the analyzed cases. Important observations from the analysis are:

- Positions 1 and 3 in Figure 8 are the two most detrimental hot spot areas for a vertical wick. The upper corner hot spot positions are critical because they are associated with the longest average flow distances for the liquid from the pool at the bottom of the wick and a higher local mass flow rate at the hot spot border. The hot spot positions 1 and 3 will lead to the lowest maximum average heat flux for the whole wick.

- Position 2 is less detrimental than position 1 and position 3 because a hot spot in position 2 will receive liquid from both sides, with a lower average flow resistance than the corner hot spots 1 and 3.

- A hot spot in position 7, 8, or 9 will lead to the highest maximum average heat fluxes because the average flow resistance is reduced compared to the uniform heat flux case. A hot spot in position 7,8 , or 9 , which may not be sufficient to cause dryout there, can still cause dryout at the top of the wick.

A dryout situation caused by a hot spot will lead to a sharp increase in the temperature at the dryout position. Mechanical damage to the wick can occur due to the thermal expansion which accompanies the dryout. An undamaged wick will normally be rewetted at the dryout position if the heat flux at the hot spot is decreased below the dryout value.

One way to reduce the risk for hot spots is to increase the thickness of the wick, because the capacity of a wick is directly proportional to its thickness. Increased thickness will, however, increase the thermal resistance of the wick.

Reduced wick height will also increase the ability of the wick to handle hot spots, and lead to increased maximum average uniform heat flux.

The conclusions of the hot spot analysis are also considered valid for wicks exposed to non-uniform heat fluxes, in general. 
Special design is required when the application requires cooling over a larger height than a single wick can handle. This may be a system consisting of several heat pipes, or a single heat pipe in which condensate is supplied to the wick at several vertical positions.

\section{Conclusions}

- From the analytical model:

For the heat pipe at an operating temperature of $500{ }^{\circ} \mathrm{C}$ the thermal resistances related to the evaporation and condensation of the working fluid were small compared to the thermal resistances of the heat pipe walls.

- From the analytical model and the experimental results:

A simplified thermal resistance spreadsheet model of the heat pipe produced operating temperatures which correlated within a $\pm 10 \%$ error band within a wide range of operating parameters. The limited amount of experiments of this study indicated that the heat transfer capacity of the heat pipe utilizing potassium working fluid was higher than predicted from theory in the vapor static pressure-limited region, in the capillary pressure-limited region the capacity was in accordance with theory when the experimental uncertainty was taken into account. In general, the wick performance may be higher than predicted due to:

A The theory of Shirazy and Fréchette [17], which says that the effective pore radius is decreasing when the wick is exposed to a heat flux, i.e., use of an effective pore radius obtained from an experiment without heat flux will underestimate the wick capacity.

B The permeability of the wick is larger than measured in experiments with the model fluid. Point A can be excluded as explanation for the high wick capacity measured in the vapor static pressure limited region, only increased permeability can lead to increased performance in that part.

- $\quad$ From analysis of the thermal expansion by use of COMSOL Multiphysics ${ }^{\circledR}$ :

The unilateral heat flux caused about $2 \mathrm{~mm}$ horizontal deformation (bending) of the experimental heat pipe. Asymmetrical thermal expansion caused by unilateral heat flux can cause thermal contact problems even for heat pipes of made of materials of relatively high thermal conductivity, like nickel, and can have created a high permeability channel in the wick in the current case.

- From the numerical 2D wick hot spot analysis:

A rectangular, vertical wick is most vulnerable to hot spots located at the upper corners, which are associated with the highest flow resistances.Heat pipe technology is promising for an aluminum electrolysis cell wall cooling system due to high effective thermal conductivity and ability to handle hot spots.

Acknowledgments: The authors would like to thank Elkem and the Research Council of Norway for funding this work.

Author Contributions: Geir Hansen carried out the experimental work, data reduction, and prepared the first draft of the paper. The hot spot analysis was done by Kolbeinn Kristjansson. Geir Hansen and Erling Næss have equally contributed to the analysis and paper preparation.

Conflicts of Interest: The authors declare no conflict of interest.

\section{Symbols}

A area, $\mathrm{m}^{2}$

$A_{c} \quad$ wick cross sectional area, $\mathrm{m}^{2}$

$c_{p} \quad$ specific heat capacity, $\mathrm{J} /(\mathrm{kg} \cdot \mathrm{K})$ 


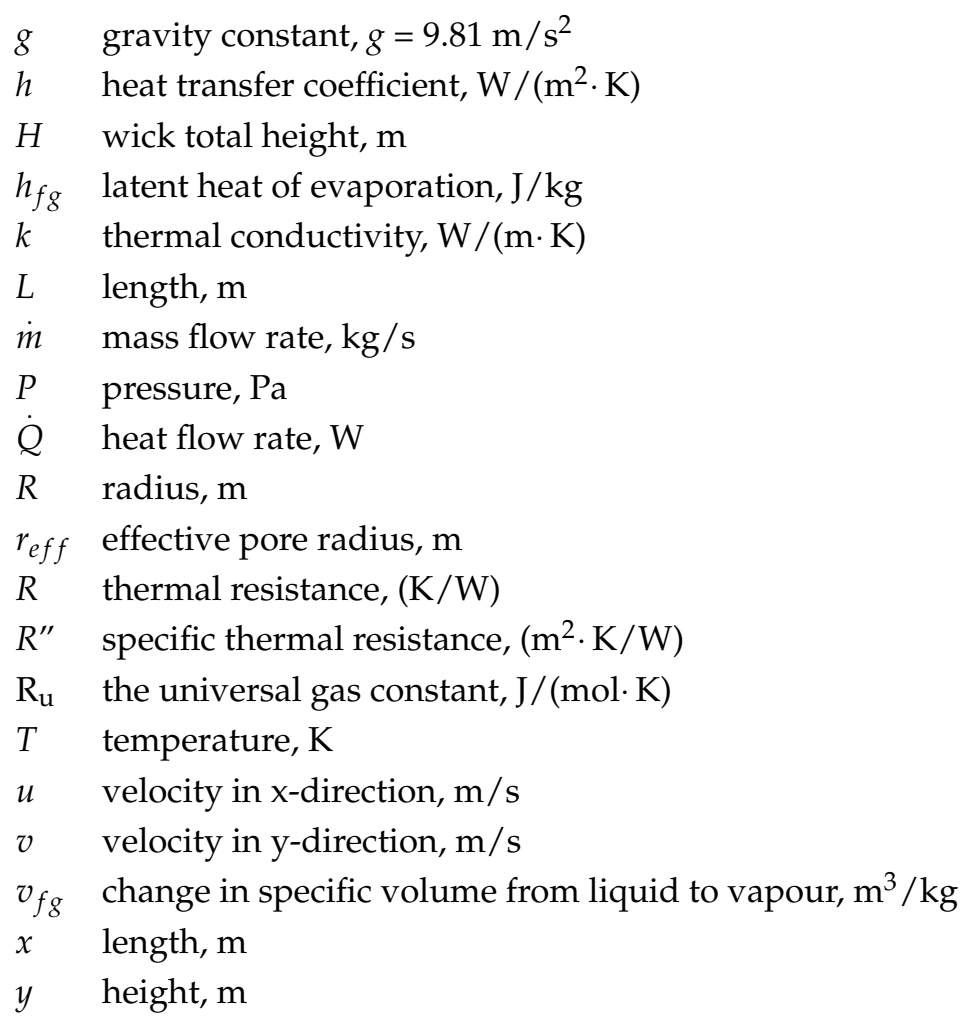

\section{Greek Symbols}

$\alpha \quad$ accomodation coefficient (dimensionless), or source $/$ sink function, $\mathrm{kg} /\left(\mathrm{m}^{2} \cdot \mathrm{s}\right)$

$\Gamma \quad$ evaporation rate per unit height of wetted wick, $\mathrm{kg} /(\mathrm{m} \cdot \mathrm{s})$

$\varepsilon$ porosity

$\kappa \quad$ permeability, $\mathrm{m}^{2}$

$\mu \quad$ dynamic viscosity, $\mathrm{kg} /(\mathrm{m} \cdot \mathrm{s})$

$\rho$ density, $\mathrm{kg} / \mathrm{m}^{3}$

$\sigma \quad$ surface tension, $\mathrm{N} / \mathrm{m}$

\section{Subscripts}

$\begin{array}{ll}\text { c } & \text { cross-section } \\ \text { cap } & \text { capillary } \\ \text { eff } & \text { effective (pore radius) } \\ f & \text { friction } \\ g & \text { gravity } \\ h s & \text { hydrostatic } \\ l & \text { liquid } \\ \text { max } & \text { maximum } \\ \text { sat } & \text { saturated } \\ v & \text { vapour }\end{array}$

\section{References}

1. Grjotheim, K.; Kvande, H. Introduction to Aluminium Electrolysis: Understanding the Hall-Héroult Process; Aluminium-Verlag: Düsseldorf, Germany, 1993.

2. Aune, J.A.; Johansen, K.; Nos, P.O. Electrolytic Cell for the Production of Aluminum and a Method for Maintaining a Crust on a Sidewall and for Recovering Electricity. U.S. Patent 6811677B2, 2 November 2004. 
3. Faghri, A. Heat Pipe Science and Technology; Taylor \& Francis: Washington, DC, USA, 1995.

4. Reay, D.A.; Kew, P.A.; McGlen, R.; Dunn, P.D. Heat Pipes: Theory, Design, and Applications; Butterworth-Heinemann, an Imprint of Elsevier: Oxford, UK, 2014.

5. Silverstein, C.C. Design and Technology of Heat Pipes for Cooling and Heat Exchange; Hemisphere Pub. Corp.: Washington, DC, USA, 1992.

6. Peterson, G.P. An Introduction to Heat Pipes: Modeling, Testing, and Applications; Wiley: New York, NY, USA, 1994.

7. Faghri, A. Review and advances in heat pipe science and technology. J. Heat Transf. 2012, 134. [CrossRef]

8. Reay, D.; Harvey, A. The role of heat pipes in intensified unit operations. Appl. Therm. Eng. 2013, 57, 147-153. [CrossRef]

9. Huang, X.; Franchi, G. Design and fabrication of hybrid bi-modal wick structure for heat pipe application. J. Porous Mater. 2008, 15, 635-642. [CrossRef]

10. Marcus, B.D.; Edwards, D.K. Graded Pore Size Heat Pipe Wick. U.S. Patent 4,170,262, 9 October 1979.

11. Chan, C.W.; Siqueiros, E.; Ling-Chin, J.; Royapoor, M.; Roskilly, A.P. Heat utilisation technologies: A critical review of heat pipes. Renew. Sustain. Energy Rev. 2015, 50, 615-627. [CrossRef]

12. Hansen, G.; Næss, E. Performance of compressed nickel foam wicks for flat vertical heat pipes. Appl. Therm. Eng. 2015, 81, 359-367. [CrossRef]

13. Queheillalt, D.T.; Carbajal, G.; Peterson, G.P.; Wadley, H.N.G. A multifunctional heat pipe sandwich panel structure. Int. J. Heat Mass Transf. 2008, 51, 312-326. [CrossRef]

14. Dullien, F.A. Porous Media: Fluid Transport and Pore Structure; Academic Press: San Diego, CA, USA, 2012.

15. International Organization for Standardization. Dense Shaped Refractory Products—Determination of Bulk Density, Apparent Porosity and True Porosity; ISO_5017; International Organization for Standardization: Geneva, Switzerland, 1998.

16. Holley, B.; Faghri, A. Permeability and effective pore radius measurements for heat pipe and fuel cell applications. Appl. Therm. Eng. 2006, 26, 448-462. [CrossRef]

17. Shirazy, M.R.S.; Fréchette, L.G. Effect of meniscus recession on the effective pore radius and capillary pumping of copper metal foams. J. Electron. Packag. 2014, 136, 041003. [CrossRef]

18. Dwyer, O.E. Boiling Liquid-Metal Heat Transfer, 1st ed.; American Nuclear Society: Hinsdale, IL, USA, 1976.

19. Rosenfeld, J.; Minnerly, K.; Dyson, C. Ten Year Operating Test Results and Post-Test Analysis of a 1/10 Segment Stirling Sodium Heat Pipe, Phase III; NASA/CR-2012-217430; National Aeronautics and Space Administration, Glenn Research Center: Cleveland, OH, USA, 2012.

20. Meisel, P.; Lippmann, W.; Hurtado, A. Ceramic high-temperature heat-pipes. In Proceedings of the 22nd International Conference on Nuclear Engineering, American Society of Mechanical Engineers, Prague, Czech Republic, 7-11 July 2014.

21. Hansen, G.; Næss, E.; Kristjansson, K. Sintered nickel powder wicks for flat vertical heat pipes. Energies 2015, 8, 2337-2357. [CrossRef]

22. Vargaftik, N.B.; Vinogradov, J.K.; Jargin, V.S. Handbook of Physical Properties of Liquids and Gases: Pure Substances and Mixtures; Begell House: New York, NY, USA, 1996.

23. Huang, X.Y.; Liu, C.Y. The pressure and velocity fields in the wick structure of a localized heated flat plate heat pipe. Int. J. Heat Mass Transf. 1996, 39, 1325-1330. [CrossRef]

24. Incropera, F.P.; DeWitt, D.P.; Bergman, T.L. Principles of Heat and Mass Transfer; Wiley: Singapore, Singapore, 2013.

25. Stephan, K.; Green, C.V. Heat Transfer in Condensation and Boiling; Springer: Berlin, Germany, 1992.

(c) 2016 by the authors; licensee MDPI, Basel, Switzerland. This article is an open access article distributed under the terms and conditions of the Creative Commons by Attribution (CC-BY) license (http://creativecommons.org/licenses/by/4.0/). 